\title{
AVALIAÇÃO DE SISTEMAS SEPARADORES \\ DE ÁGUA E ÓLEO EM POSTOS DE COMBUSTÍVEIS
}

\author{
Larissa Boenso Brandão Peixoto - larissabrandao.eng@gmail.com \\ Faculdade Araguaia
}

Fernando Ernesto Ucker - ferucker@gmail.com

Faculdade Araguaia 




\section{RESUMO}

Tendo em vista o aumento da demanda de serviços voltados ao mercado automobilístico no Brasil, a atividade de revenda de combustíveis tem expandido consideravelmente nos últimos anos. Esta atividade é potencialmente poluidora e assim passível de licenciamento ambiental. Neste contexto este estudo teve como objetivo avaliar sistemas separadores de água e óleo em postos de combustíveis por meio de coleta de amostras de efluente das saídas dos sistemas separadores. Os resultados analíticos das amostras indicam que os sistemas separadores possuem boa eficiência na remoção de sólidos sedimentáveis, bem como na remoção de óleos e graxas contidos nos efluentes. Tais resultados comprovam a importância da instalação destes sistemas em postos de combustíveis, visto que, se lançados sem tratamento prévio nas redes de esgotos os efluentes podem causar danos aos sistemas de esgotamento, instalações de estações de tratamento de esgoto, além de possível contaminação de corpos hídricos receptores de esgoto tratado.

Palavras-chave: Sistemas separadores de água e óleo, impacto ambiental, efluente. 


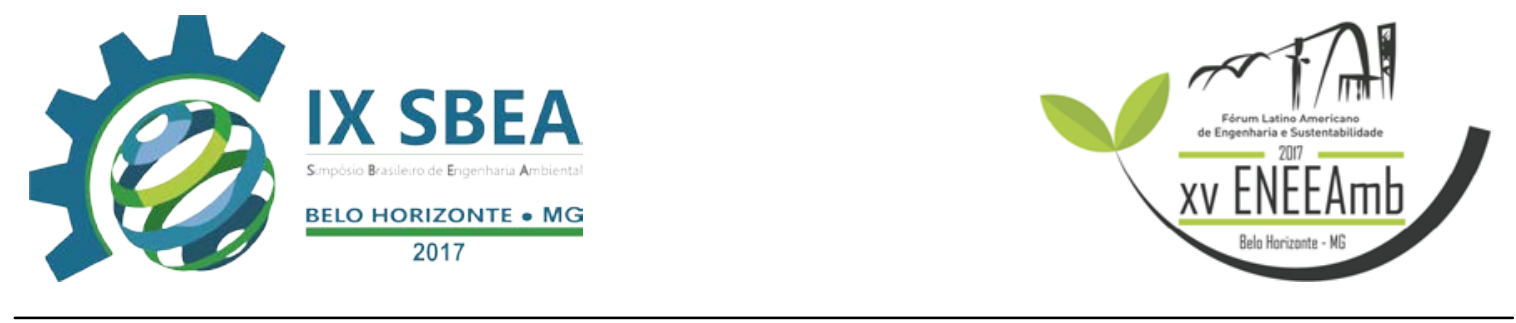

\section{INTRODUÇÃO/OBJETIVO}

Tendo em vista o aquecimento do mercado automobilístico no Brasil nos últimos anos, é natural que haja também um crescimento no número de empreendimentos especializados voltados a atender esta demanda. Assim como as demais atividades que tangem o mercado automobilístico, o ramo de revenda de combustíveis para veículos automotores segue a tendência de crescimento do mercado. Segundo dados da Agencia Nacional de Petróleo - ANP, atualmente no Brasil existem mais de 39 mil postos de serviços instalados em todo o território nacional, o que significa um aumento de cerca de $10 \%$ no número de postos existentes no país nos últimos 10 anos (ANP, 2014).

De modo geral na última década houve uma intensificação nas discussões acerca do meio ambiente no Brasil e no mundo com objetivo de conscientizar e estabelecer uma nova postura tanto das áreas industriais e comerciais como da sociedade em geral. Neste âmbito a atividade de revenda de combustíveis para veículos automotores passou a ser considerada a partir do ano de 2000 uma atividade potencialmente poluidora e assim uma atividade passível de licenciamento ambiental conforme a Resolução No 273 do Conselho Nacional do Meio Ambiente - CONAMA, devido a seu potencial de poluição (CONAMA, 2000).

Uma das principais preocupações no que toca um posto de combustíveis é quanto ao lançamento dos seus efluentes, devido à grande concentração de contaminantes, principalmente por óleos e graxas dissolvidos nas águas residuais desta atividade, visto que alguns postos oferecem além do serviço de abastecimento também os serviços de troca de óleo e lavagem de veículos. Sabe-se que um mau gerenciamento destes efluentes pode acarretar em sérios danos aos mananciais receptores das grandes cidades além de comprometer os canais de escoamento das redes de esgotamento sanitário. Deste modo é recomendado que todo posto realize um tratamento prévio de seus efluentes por meio de um sistema separador de água e óleo. É sabido que os efluentes contendo óleos e graxas são prejudiciais ao sistema de esgotamento sanitário podendo até obstruir redes e tubulações. 




O óleo lubrificante residual proveniente das atividades cotidianas dos postos de serviços se disposto aos corpos hídricos, ou até mesmo ao solo, pode acarretar em grandes impactos ambientais. Segundo a Associação de Proteção do Meio Ambiente de Cianorte (APROMAC), o óleo lubrificante contém diversos elementos tóxicos, como cádmio, cromo e chumbo (APROMAC, 2005).

Neste contexto o presente estudo teve como objetivo avaliar a eficiência dos sistemas de separação de água e óleo provenientes das atividades de postos de combustíveis.

\section{METODOLOGIA}

Para o desenvolvimento desse estudo foram selecionados três postos revendedores de combustíveis para veículos automotores, onde foram coletadas amostras de efluente das saídas dos sistemas separadores de água e óleo existentes nos empreendimentos. Os mesmos então situados no município de Brasília, no Distrito Federal. O Quadro 1 apresenta a localização dos empreendimentos estudados, conforme coordenadas geográficas UTM (Figura 1, Figura 2 e Figura 3).

Quadro 1 - Localização dos empreendimentos.

\begin{tabular}{|c|c|c|c|}
\hline \multirow{2}{*}{ Empreendimento } & \multicolumn{3}{|c|}{ Coordenadas UTM } \\
\cline { 2 - 4 } & Zona & Longitude E (m) & Latitude S (m) \\
\hline Empreendimento 1 & 22 L & 814032,00 & 8249811,00 \\
\hline Empreendimento 2 & 22 L & 810812,00 & 8246841,00 \\
\hline Empreendimento 3 & 22 L & 809196,00 & 8251062,00 \\
\hline
\end{tabular}



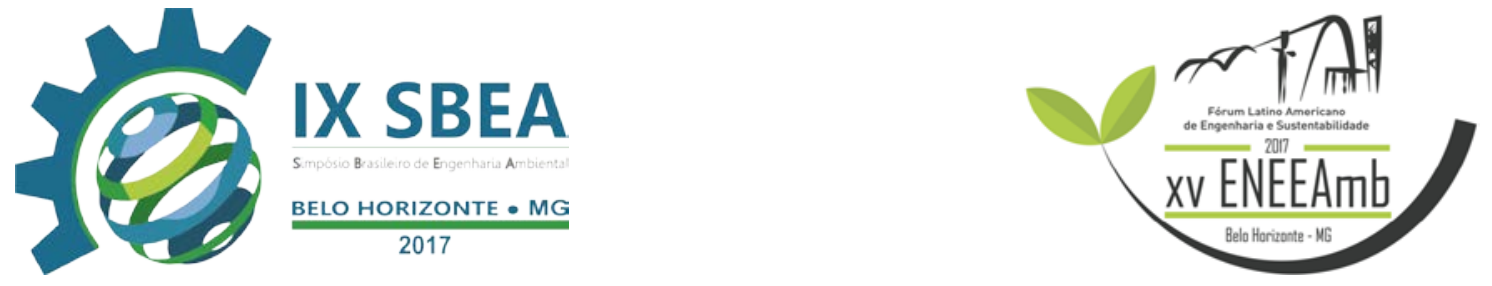

Figura 1 - Localização do empreendimento 1.

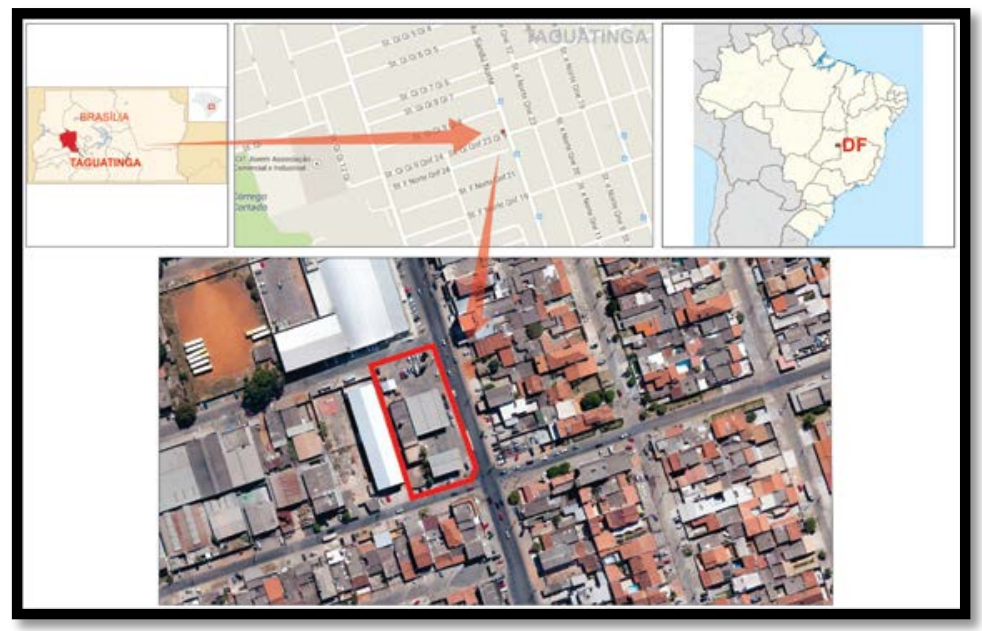

Figura 2 - Localização do empreendimento 2.



Figura 3 - Localização do empreendimento 3.




Em todos os casos avaliados, os empreendimentos estão localizados na zona urbana de Brasília, em uma circunvizinhança de característica mista (comercial/residencial). A região metropolitana de Brasília possui área de 5.779,999 km2 e um quantitativo populacional estimado em 2.789.761 de habitantes, conforme dados de 2013 do Instituto Brasileiro de Geografia e Estatística (IBGE, 2013). Ainda sobre a localização dos postos de serviços em questão, vale ressaltar que todos estão situados em regiões dotadas de sistema público de esgotamento sanitário e redes públicas de drenagens de águas pluviais.

\section{Características físicas dos empreendimentos}

O primeiro empreendimento (Figura 1), chamado neste trabalho de Posto 1, possui sistema de drenagem oleosa - SDO, composto por canaletes coletores de efluentes que posteriormente os direcionam ao sistema separador de água e óleo - SAO. O sistema separador deste empreendimento é composto por duas SAO’s, sendo uma responsável por receber os efluentes advindos da pista de abastecimento 2 e área de troca de óleo (SAO-1) e outra responsável por receber os efluentes oriundos da pista de abastecimento 1 e áreas de lavagem de veículos (Figura 4).

O segundo empreendimento (Figura 2), neste chamado de Posto 2, conta também com SDO composto por canaletes coletores de efluentes que os direcionam ao sistema separador. O sistema separador de água e óleo do empreendimento é formado por duas SAO's, onde uma recebe os efluentes provenientes da pista de abastecimento e troca de óleo (SAO-1) e a outra recebe os efluentes de origem da área de lavagem de veículos (Figura 5).

O terceiro empreendimento (Figura 3), chamado neste trabalho de Posto 3, assim como os demais postos de serviços analisados possui SDO formado por canaletes que direcionam os efluentes gerados na pista de abastecimento e área de troca de óleo para o sistema separador de água e óleo (Figura 6).

Cabe ressaltar que com exceção do Posto 3, que oferece os serviços de revenda de combustíveis, troca de óleo e lubrificação de veículos automotores, os demais empreendimentos oferecem ainda o serviço de lavagem de veículos. Em todos 
os casos as SAO’s são construídas de quatro compartimentos, sendo elas caixa desarenadora, caixa separadora de água e óleo, caixa coletora de óleo e caixa de inspeção.

Figura 4 - Croqui do empreendimento 1 com detalhamento do sistema separador de água e óleo.

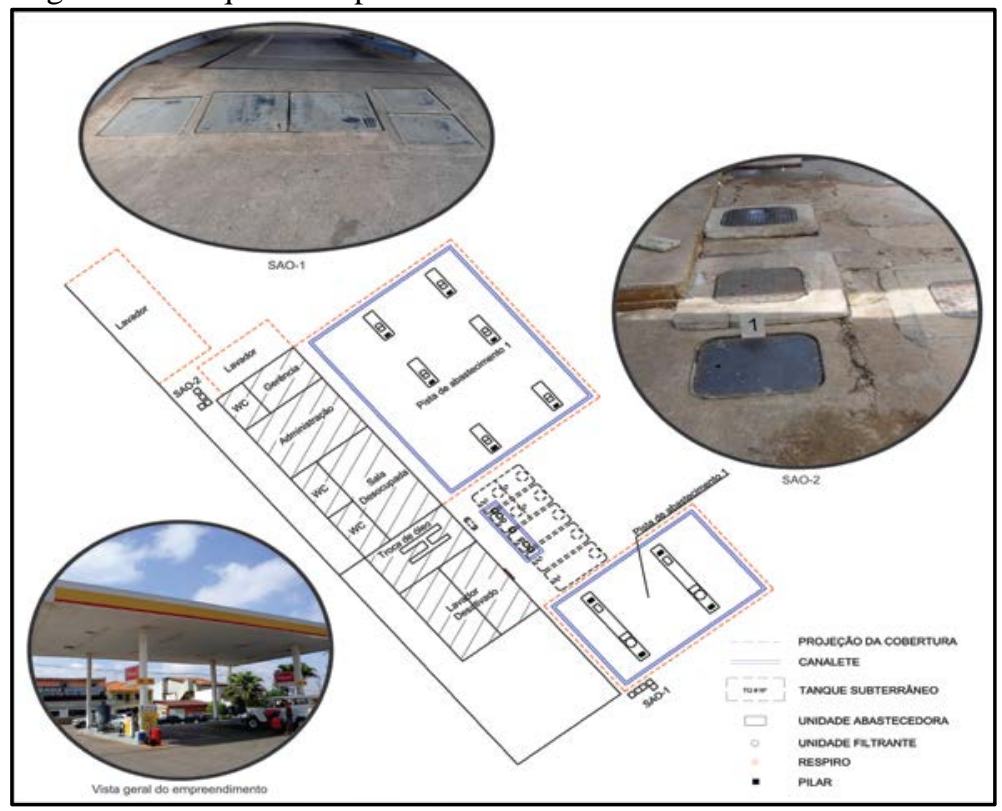

Figura 5 - Croqui do empreendimento 2 com detalhamento do sistema separador de água e óleo.

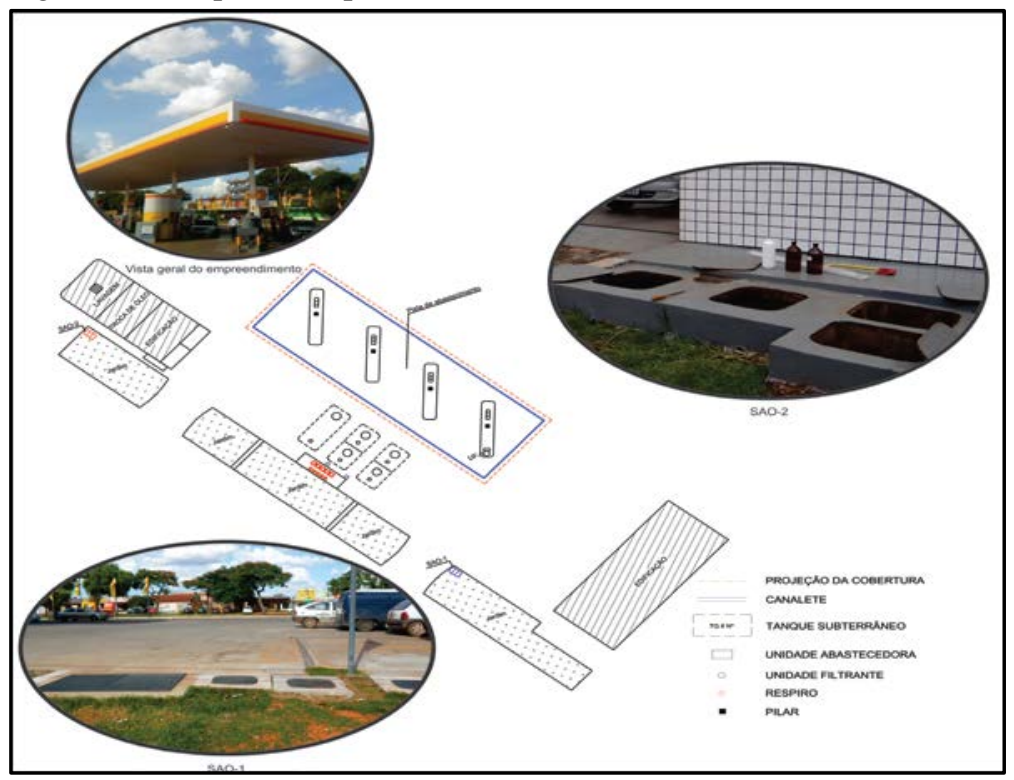




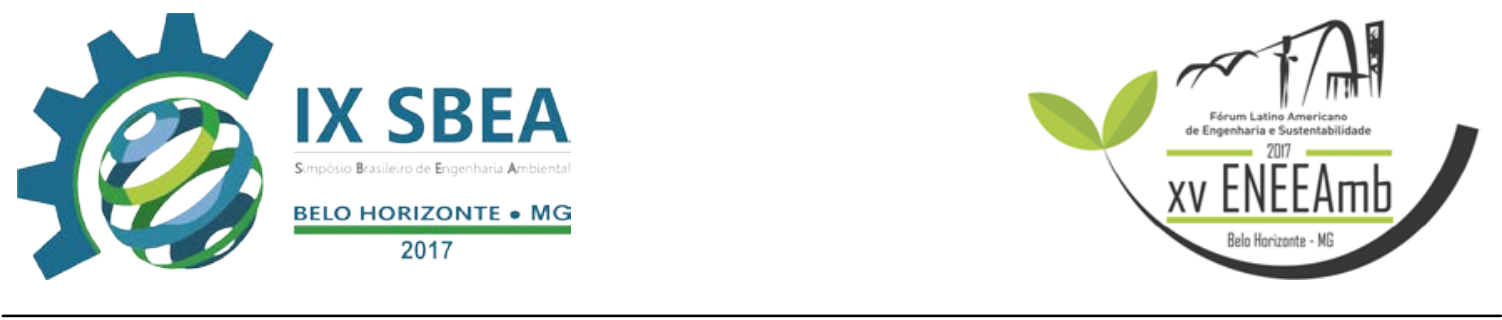

Figura 6 - Croqui do empreendimento 2 com detalhamento do sistema separador de água e óleo.

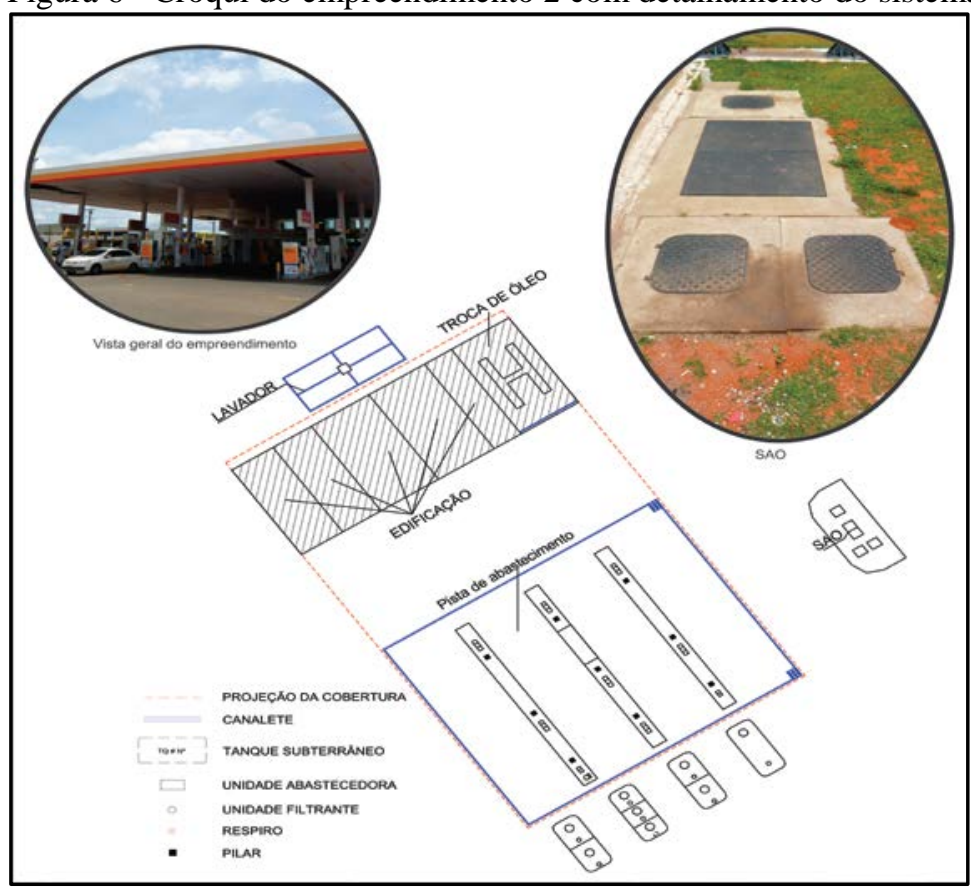

As amostras foram coletadas em duplicata com auxílio de bailers descartáveis, conforme as datas descritas no Quadro 2. Posteriormente, foram armazenadas em frascos específicos e foram mantidas refrigeradas, para que não houvesse alterações de suas características químicas durante os procedimentos de envio ao laboratório que realizou as análises. O sistema de armazenamento das amostras utilizado era adiabático (sem troca de calor com o ambiente externo) e fechado (sem troca de massa com o exterior), portanto a temperatura tendeu a se manter estável durante o transporte do material.

Quadro 2. Local de coleta das amostras de efluente geradas nos postos de combustíveis do município de Brasília - DF, e suas respectivas datas de coleta.

\begin{tabular}{|c|c|c|}
\hline Local de coleta da amostra & Data da coleta & Parâmetros Analisados \\
\hline $\begin{array}{c}\text { Saída da SAO-1 } \\
\text { Posto 1 }\end{array}$ & $19 / 09 / 2014$ & $\mathrm{pH}$, Óleos e graxas e sólidos sedimentáveis \\
\hline $\begin{array}{c}\text { Saída da SAO-2 } \\
\text { Posto 1 }\end{array}$ & $19 / 09 / 2014$ & $\mathrm{pH}$, Óleos e graxas e sólidos sedimentáveis \\
\hline $\begin{array}{c}\text { Saída da SAO-1 } \\
\text { Posto 2 }\end{array}$ & $23 / 11 / 2013$ & $\mathrm{pH}$, Óleos e graxas e sólidos sedimentáveis \\
\hline $\begin{array}{c}\text { Saída da SAO-2 } \\
\text { Posto 2 }\end{array}$ & $23 / 11 / 2013$ & $\mathrm{pH}$, Óleos e graxas e sólidos sedimentáveis \\
\hline $\begin{array}{c}\text { Saída da SAO } \\
\text { Posto 3 }\end{array}$ & $08 / 01 / 2014$ & $\mathrm{pH}$, Óleos e graxas e sólidos sedimentáveis \\
\hline
\end{tabular}


As metodologias de análise para os parâmetros de avaliação do efluente estão de acordo com Standard Methods for the Examination of Water and Waste (APHA, 2012) e o laboratório responsável pelas análises foi o Aqualit Tecnologia em Saneamentos LTDA, localizado na cidade de Goiânia, GO. O Quadro 3 expressa a identificação das metodologias adotadas pelo laboratório para a realização das análises mencionadas anteriormente.

Quadro 3. Identificação das metodologias para avaliação do efluente.

\begin{tabular}{|c|c|}
\hline Análises & Identificação da Metodologia \\
\hline $\mathrm{pH}$ & SMWW 4500 - H+ \\
\hline Óleos e graxas & SMWW 5220 D \\
\hline Sólidos Sedimentáveis & SMWW 2540 F \\
\hline
\end{tabular}

Para a realização de todas as análises conforme metodologias utilizadas foram necessárias às coletas de $3.000 \mathrm{~mL}$ de efluente de cada SAO, conforme demonstrado no Quadro 4.

Quadro 4. Identificação das metodologias para avaliação do efluente.

\begin{tabular}{|c|c|}
\hline Parâmetros & Quantidade Amostrada \\
\hline $\mathrm{pH}$ & $1000 \mathrm{~mL}$ \\
\hline Óleos e graxas & $1000 \mathrm{~mL}$ \\
\hline Sólidos sedimentáveis & $1000 \mathrm{~mL}$ \\
\hline
\end{tabular}

\section{RESULTADOS E DISCUSSÃO}

Os resultados analíticos das amostras dos efluentes foram comparados com os valores estabelecidos pela Resolução n 430/2011 do Conselho Nacional do Meio Ambiente - CONAMA (BRASIL, 2011), que dispõe sobre os critérios para lançamento de efluentes líquidos e com o Decreto nº 18.328/1997 - Companhia de Saneamento Ambiental do Distrito Federal (CAESB, 1997), que dispõe sobre o padrão de lançamento de efluentes líquidos na rede coletora de esgotos (Quadro 5).

Quadro 5 - Resultados das análises dos efluentes.

\begin{tabular}{|c|c|c|c|c|c|}
\hline Parâmetro & $\begin{array}{c}\text { Decreto no 18.328 } \\
\text { 08/06/1997 Tabela } \\
\text { II - CAESB }\end{array}$ & $\begin{array}{c}\text { CONAMA } \\
430 / 2011\end{array}$ & Unidade & $\begin{array}{c}\text { AE/SAO- } \\
1\end{array}$ & $\begin{array}{c}\text { AET/SAO } \\
-2\end{array}$ \\
\hline
\end{tabular}




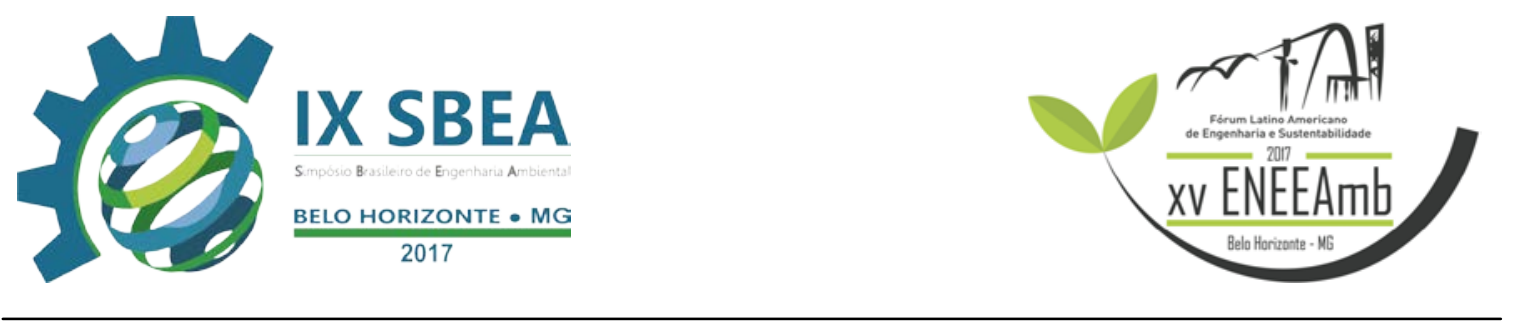

\begin{tabular}{|c|c|c|c|c|c|}
\hline \multicolumn{6}{|c|}{ Posto 1} \\
\hline $\mathrm{pH}$ & 6 a 10 & 5 а 9 & - & 7,0 & 6,5 \\
\hline Óleos e Graxas & $150 \mathrm{mg} / \mathrm{L}$ & 20,0 & $\mathrm{mg} / \mathrm{L}$ & 2,45 & 9,73 \\
\hline $\begin{array}{c}\text { Sólidos } \\
\text { Sedimentáveis }\end{array}$ & 20 mL/L & 1 & $\mathrm{~mL} / \mathrm{L}$ & 0,50 & 0,20 \\
\hline \multicolumn{6}{|c|}{ Posto 2} \\
\hline $\mathrm{pH}$ & 6 a 10 & 5 a 9 & - & 7,2 & 7,3 \\
\hline Óleos e Graxas & $150 \mathrm{mg} / \mathrm{L}$ & 20,0 & $\mathrm{mg} / \mathrm{L}$ & 4,7 & 1,8 \\
\hline $\begin{array}{c}\text { Sólidos } \\
\text { Sedimentáveis } \\
\end{array}$ & 20 mL/L & 1 & $\mathrm{~mL} / \mathrm{L}$ & $<0,1$ & 0,2 \\
\hline \multicolumn{6}{|c|}{ Posto 3} \\
\hline $\mathrm{pH}$ & 6 a 10 & 5 а 9 & - & 6,7 & - \\
\hline Óleos e Graxas & $150 \mathrm{mg} / \mathrm{L}$ & 20,0 & $\mathrm{mg} / \mathrm{L}$ & 1,4 & - \\
\hline $\begin{array}{c}\text { Sólidos } \\
\text { Sedimentáveis }\end{array}$ & 20 mL/L & 1 & $\mathrm{~mL} / \mathrm{L}$ & 0,1 & - \\
\hline
\end{tabular}

Segundo MELO et al (2002) estudos constataram que concentrações acima de $65 \mathrm{mg} / \mathrm{L}$ de óleos e graxas seriam suficientes para ocasionar danos operacionais ao sistema convencional de esgotamento sanitário. Além disso, conforme a cartilha de instrução para instalação de sistema separadores da Companhia de Saneamento Ambiental do Distrito Federal (CAESB, ANO), o despejo de sólidos sedimentáveis e óleos e graxas nos sistemas de esgotamento podem causar obstruções das redes, danos a instalações sanitárias e até mesmo comprometimento das instalações de uma Estação de Tratamento de Esgotos - ETE.

Ainda sobre a ocorrência de danos em sistemas devido ao lançamento de óleos e graxas no esgoto é importante salientar que segundo APHA (1992) uma quantidade excessiva de óleos e graxas em um efluente de tratamento primário pode interferir no tratamento biológico, promovendo a formação de um filme sobre a superfície líquida, impedindo a entrada de luz e assim comprometendo a aeração. No tratamento das águas residuária, os óleos e graxas costumam ser resistentes à digestão anaeróbica, causando acúmulo de espumas nos digestores, provocando odores desagradáveis. 


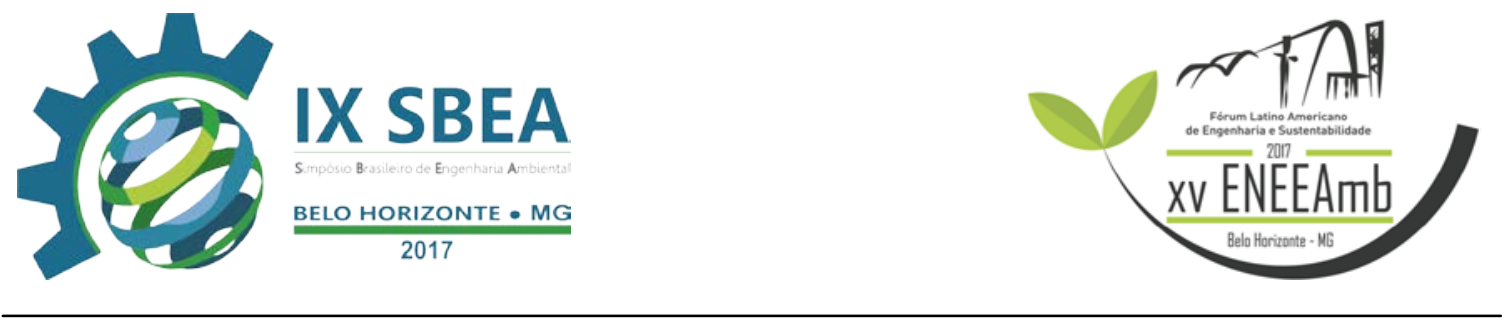

Conforme observado no Quadro 5, os resultados analíticos das amostras de efluentes das SAO’s indicaram resultados que estão dentro dos padrões estabelecidos pelo CONAMA e pela CAESB.

Estes resultados indicam que os sistemas de separação de água e óleo existentes nos empreendimentos avaliados possuem boa eficiência na retenção de óleos e graxas e sólidos sedimentáveis. Este fato comprova a importância de se ter um sistema de tratamento prévio de efluentes em um posto de serviços onde as atividades como troca de óleo e lavagem de veículos tem uma considerável geração de efluentes contaminados e que se não passarem por uma pré-tratamento, alcançariam as redes coletoras de esgotos, estações de tratamento e posteriormente corpos hídricos receptores de esgoto tratado.

\section{CONCLUSÕES/RECOMENDAÇÕES}

As amostras de efluentes retiradas das saídas dos sistemas separadores de água e óleo foram analisadas e comparadas com a Resolução n 430/2011 do Conselho Nacional do Meio Ambiente - CONAMA e com o Decreto n ${ }^{\circ}$ 18.328/1997 Companhia de Saneamento Ambiental do Distrito Federal. Com isso, pudemos concluir que o sistema de separação de água e óleo dos três postos de gasolina que estão localizados no município de Brasília, estão dentro dos padrões estabelecidos por lei e possuem uma eficiência satisfatória.

\section{REFERÊNCIAS BIBLIOGRÁFICAS}

ANP. Agência Nacional do Petróleo, Gás Natural e Biocombustíveis, Anuário Estatístico Brasileiro do Petróleo, Gás Natural e Biocombustíveis 2009. Disponível em: $<$ http://www.anp.gov.br>.

APHA, AWWA WPCF. Standard methods for the examination of water andwastewater. 21th edition. Wasghington D.C. American Public HealthAssociation, 2012. 953p. 


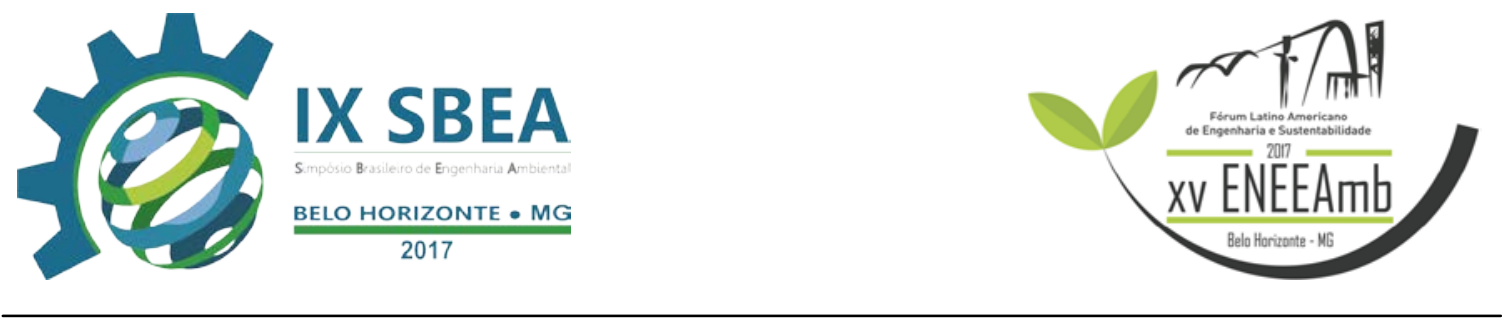

APHA. Compendium of methods for the examination of foods. American Public Health association. 3rd ed., Washington: 1992. 121p.

APROMAC - Associação de Proteção ao Meio Ambiente de Cianorte. Relatório de Gestão no Conselho Nacional do Meio Ambiente - CONAMA: justificativa da opção pelo rerrefino. Cianorte: APROMAC, mar. 2005.

BRASIL. Conselho Nacional do Meio Ambiente - CONAMA. Resolução n 273, de 29 de novembro de 2000. Estabelece diretrizes para o licenciamento ambiental de postos de combustíveis e serviços e dispõe sobre a prevenção e controle da poluição. Disponível em:

http://www.mma.gov.br/port/conama/legislacao/CONAMA_RES_CONS_2000_273.pd f> Acesso em: 17 de maio de 2017.

BRASIL. Conselho Nacional do Meio Ambiente - CONAMA. Resolução n ${ }^{\mathbf{0}}$ 430, de 13 de maio de 2011. Dispõe sobre as condições de lançamento de efluentes, complementa e altera a Resolução ${ }^{\circ}$ 357, de 17 de março de 2005, do Conselho Nacional do Meio Ambiente - $\quad$ CONAMA. 9p. Disponível em: $<$ http://www.legislacao.mutua.com.br/pdf/diversos_normativos/conama/2011_CONAM A_RES_430.pdf $>$. Acesso em: 20 de nov. 2014.

MELO, Normando, MELO, Josette; NETO, Cícero; GUIMARÃES, Adriana. Estudo Estatístico da Distribuição do Teor de Óleos e Graxas em Esgotos Domésticos e Efluentes de Filtros Anaeróbios. Rio Grande do Norte, 2002. 